\title{
A Fuzzy Logic based Efficient Routing Strategy for Ad hoc Cognitive Radio Network
}

\author{
Poonam Mittal $^{1}$, C.K. Nagpal ${ }^{2}$, Shailender Gupta ${ }^{3}$ and Kartikay Garg ${ }^{4}$ \\ YMCA University of Science and Technology, Faridabad, India \\ 1poonamgarg1984@gmail.com, ${ }^{2}$ nagpalckumar@rediffmail.com, \\ ${ }^{3}$ shailender81@gmail.com, ${ }^{4}$ kartikaygarg@ieee.org
}

\begin{abstract}
Due to exponential growth in the number of wireless devices, with each one exchanging huge amount of data, requirement for the spectrum in almost all bands has risen very sharply making it a very expensive commodity. The availability of spectrum is limited and its demand is monotonically increasing. To overcome the challenge, a solution has been proposed in the form of Cognitive Radio Network (CRN) which has both primary and secondary users. The primary users (PUs) make use of purchased licensed band while secondary users (SUs) make use of unutilized band of PUs' in the opportunistic manner. Due to their dependency upon the leftover spectrum of PUs, it is a challenging task to ensure reliable and efficient communication between the SUs. The literature contains several protocols to carry out the task but most of these protocols (almost 70\%) look for the efficiency relating to a specifically chosen parameter. The other few protocols try to take care of multi-parameter aspect but are unable to manage the scenario in totality wherein a rise in the performance of one/two parameter(s) results in the sharp degradation of other performance parameters. This paper presents a routing protocol for CRN-SUs wherein the multi-parameter optimization has been done using fuzzy rule base. The proposed protocol was simulated using fuzzy tool of Matlab-09. The simulation results show that the proposed protocol is better performer than commonly used spectrum aware shortest path routing scheme employed in ad hoc cognitive radio networks.
\end{abstract}

Keywords: Cognitive radios, Fuzzy logic, Ad hoc network, QoS, Routing protocols

\section{Introduction}

The various surveys on spectrum utilization have indicated that permanent static allocation of fixed spectrum to licensed users is an inappropriate strategy leading to unutilized spectrum which is vacant for most of the times. A survey carried out in United States by Federal Communication Commission [1] observed that many spectrum bands allocated through static assignment policies are most of times utilized over a specific duration of time or in a particular geographical region. The survey showed that the average utilization of various bands is in between $15 \%$ to $85 \%$ indicating a big wastage of scarcely available commodity known as bandwidth. Under this circumstance, it is a good idea to allow the other users to make use of the available spectrum in the opportunistic manner when it is not being used by its primary users. The concept of SUs in CRN is a welcome step in this direction.

In Ad hoc CRN set of available channels vary with time depending upon the PU putting a big challenge to ensure effectively and reliable communication at different frequencies at different times [2-3]. A problem which is nonexistent in normal ad hoc network which operate on fixed allocated band. Thus it is not possible to deploy the

Received (May 25, 2017), Review Result (August 28, 2017), Accepted (September 1, 2017) 
normal routing strategies [4] on Ad hoc networks in SU-CRN. The chosen communication mechanism should not only be a reliable one but has to be efficient one as well. The parameters chosen for the efficiency can be power consumption, hop count, delay, throughput [5] etc. The CRN literature contains several routing strategies to find the suitable and efficient paths from source to destination. These routing strategies can be classified into two categories:

- Those which take single performance metric

- Those which take more than one performance metric

A normal survey on these papers shows that the routing strategies based upon single performance metric are quite inefficient on rest of parameters. Even those which take more than one performance metric into account are unable to create a balance between various performance parameters leading to lopsided performance. The authors are of the opinion that a routing protocol based upon various performance metrics must ensure a balanced optimal act with respect to all the parameters under consideration to ensure proper quality of service (QoS). This paper is an effort in this regard. The proposed routing scheme is based on fuzzy logic wherein crisp values of QoS parameters are provided as input to a rule based Fuzzy Expert System (FES) that infers optimal path as output.

The rest of the paper is organized as follows: Section 2 contains literature survey and problem identification. Section 3 talks about the proposed routing scheme. Section 4 provides simulation set up details and flow graph of proposed scheme. Section 5 discusses the performance of the proposed scheme in comparison to Shortest Spectrum Aware Routing Scheme. Section 6 concludes the work presented in the paper and talks about its possible future extension.

\section{Literature Survey and Problem Identification}

The performance of any network is highly dependent upon the quality of routing decisions. A well connected network can yield poor results and faults in case of inappropriate routing decisions. The situation become even complex if the routing decisions are made in the decentralized manner and that too for a transmission to be carried out on leftover spectrum. This leads to limited options wherein incorporating efficacy is quite difficult task.

Under the circumstances, most of the routing schemes proposed for CRN are based single parameter performance. A few routing strategies have also been proposed that consider multi parameter performance but are unable to carry out proper optimization. This section discusses some of the prevalent/proposed routing strategies for CRN and their limitations.

- Spectrum aware On-demand Routing Protocol (SORP): This protocol [6] while making a routing decision takes into account the estimated Switching Delay (between different frequency spectrums) and the Back-off Delay (occurs due to collisions) of the channel being selected. The drawback of the protocol is the absence of any scheduling policy relating to multiple channels.

- Delay motivated on-demand Routing Protocol (DORP): This protocol [7] makes routing decision in the light of available frequency bands and queuing delay. If at the time of switching, a channel with same frequency is available then the routing is preferred through that channel. Its drawback is that it does not have any preference for the path which have PU node.

- Minimum Weight routing Protocol (MWRP): This protocol [8] considers power consumption as the performance metric for path selection. To ensure the least power consumption nearest neighbour node is selected (transmission power being 
proportional to $\mathrm{d}^{2}$ ). The protocol considers two path scenarios: One with obstacle (such as river between nodes) and obstacle free. A path with the obstacle(s) consumes more power than one without obstacle. Among the available paths say P1, P2, $\mathrm{Pk}$ one with least power consumption is selected. Since PDR, delay, hop count etc. are not considered in making routing decision hence the performance of the system may not be that good at times.

- Multi-hop Single-transceiver CRN Routing Protocol (MSCRP): This protocol [9], ensure the reliable communication by creating awareness about the available/ busy channels in the network. The channel scheduling rights are available with few selected nodes. A switching node sends a leave/join message to the scheduling node as and when it leaves/ takes over a channel announcing the vacancy/ occupancy of the channel. The scheduling nodes take decision about the channel allocation for CRN node desirous to send data. One of the major drawbacks of the protocol is its ignorance towards queuing delay.

- Spectrum Aware Mesh Routing (SAMER): This protocol [10] efficiently utilizes the available spectrum in opportunistic manner. The hallmark of the protocol is its ability to adapt to the dynamic spectrum conditions and making a quality assessment of the situation. It builds a forwarding mesh dynamically that is updated periodically and offers a set of candidate routes to the destination. Among the candidate routes, it is able to route the traffic over the path where the spectrum availability is better in terms of duration and bandwidth. Balance between long-term route stability and short-term opportunistic performance is the main advantage of SAMER. The major drawback of the protocol is its ignorance towards transmission power consideration.

- Spectrum Aware Routing Protocol (SPEAR): The main focus of SPEAR [12] is on the maximization of throughput. The hallmark of the protocol is its ability to create robust multi-hop path formation using integrated spectrum scenario. This is in contrast to the other protocols which lack in throughput performance due to reach ability problem occurring because of location-dependent channel availability. SPEAR establishes robust paths in diverse spectrum conditions and provides near-optimal throughput and end-to-end packet delivery latency and is therefore quite suitable for disaster recovery and military operations. Its major drawback is its ignorance towards other performance parameters with exclusive concentration on throughput.

- Spectrum-Tree based On-Demand Routing Protocol (STOD-RP): STOD-RP tries to solve the problem of spectrum decision and route selection in an integrated manner [14]. This is done by building a spectrum-tree in each spectrum band. Each spectrumtree selects only one root node which stores the route information to other nodes in the spectrum-tree. The protocol ensures route stability and delays are quite less.

- Ant-Based Spectrum Aware Routing (ASAR): ASAR [16] is a biologically enthused routing solution for CRN wherein paths are discovered, observed and learned by guided ant-communication. The protocol uses F-ants to explore paths which are feasible in context of spectrum to the destinations. Periodic information about the network and updating routing table is the role of B-ants. A reinforcement learning functions is used to accelerate convergence to find a better path. The biggest drawback of the protocol is the requirement and generation of large numbers of antpackets for establishing routes leading to long delay in route creation and huge energy consumption making it highly unsuitable for large size CRN.

- Spectrum Aware routing protocol for Cognitive ad-Hoc networks (SEARCH): SEARCH is based upon AODV routing protocol [19]. Each node in the network is equipped with a single tunable radio transceiver and has location awareness. The location information is exchanged among neighbours periodically by using beacon 
updates. The protocol uses the location awareness information to perform geographic routing in which channel and path selection process eludes areas of PU activity.

- Spectrum Aware Opportunistic Routing (SAOR): In a CRN consisting of multi radio systems, a routing scheme should be capable of utilizing numerous links opportunities in order to enhance spectrum utilization. But most of the routing schemes are unable to make full utilization of this highly dynamic available links. To overcome this problem, Spectrum Aware Opportunistic Pouting (SAOR) [22] protocol was introduced for the CRN. Here communication is through wireless fading channels. SAOR employs a cooperative scheme to enable multi-path transmissions and maintains the statistical QoS guaranteed throughput for practical applications. Local sensing information is used as an innovative approach for establishing the spectrum map and routing metrics are derived for opportunistic links known as Opportunistic Link Transmission (OLT), the opportunistic path metrics, and the CR node metrics. However, the procedure of finding opportunistic links leads to increase in end to end delay.

- Gymkhana: This protocol [29] looks for the route which is stable and has better connectivity. This is done by avoiding the network zones that do not guarantee stable and high connectivity. Gymkhana uses a distributed mechanism to collect vital information about key parameters related to possible paths from source to destination. These parameters are then analyzed using Laplacian graphs that evaluates different routing paths and computes most efficient routing paths.

- Energy-Efficient QoS Routing (EQR): EQR is an on-demand QoS routing protocol, based upon DSR, for CRANs that reserves bandwidth on a per flow basis using TDMA [32]. The protocol is a session-oriented application and is suitable for small CRANs whose topologies change at low to medium rate. A session specifies its QoS requirement in the form of number of transmission timeslots needed for a route from source to destination. For each session (flow), the QoS routing protocol will find the route, the channel and the number of timeslots for each link on the route. The drawback of the protocol is its ignorance towards the transition properties of available channels for making routing decisions.

El Masri proposed the idea of a fuzzy logic based routing scheme [41] that achieves a good trade-off between availability of channels, transmission ability of the nodes and stability of the path. Fuzzy logic is used to combine and compute these metrics in order to make suitable routing decisions. The stability of a path is determined by channel transmission rate and transmission power. Different path grades are computed to indicate stability of path. The main objective is to increase channel availability when the stable routes are established. The stability metric evaluates the utilization efficiency of channels by capturing their sporadic availability to cognitive users. The predicted power metric estimates the spectrum capabilities for the on-going transmission without interrupting licensed users. The major drawback of the protocol is that it consider only the stability of the path and is ignorant towards its reliability, more in some cases residual energy is also a cause of concern.

A novel routing protocol for CRN was proposed [42] in which hop count, delay, transmission power and spectrum awareness are considered as performance metric for path selection but throughput was not considered. This protocol provides better results comparative to shortest path routing and minimum transmission power routing schemes. This routing did not use any inference mechanism for better impact analysis.

Beside the above mentioned protocols, many more routing schemes have been proposed, some of which are briefly presented in Table 1 . 
Table 1. Brief Survey of Some More CRN Routing Protocols

\begin{tabular}{|c|c|c|}
\hline Routing Scheme & Merit(s) / Feature(s) & Drawback(s) \\
\hline $\begin{array}{l}\text { Local co-ordination based } \\
\text { routing[11] }\end{array}$ & $\begin{array}{l}\text { - Traffic redirection to neighbor nodes for } \\
\text { load balancing } \\
\text { - Low cumulative delay } \\
\text { - Less end to end delay } \\
\text { - Link failure handling }\end{array}$ & $\begin{array}{l}\text { - Frequent exchange of additional } \\
\text { control packets causes bandwidth } \\
\text { wastage }\end{array}$ \\
\hline $\begin{array}{l}\text { Anti-intermittence Source } \\
\text { routing protocol, (AiSorp) } \\
\text { [13] }\end{array}$ & $\begin{array}{l}\text { - Route established once work for long time } \\
\text { - Modified route maintenance algorithm }\end{array}$ & $\begin{array}{l}\text { - Uses pre- defined assumptions } \\
\text { and parameters }\end{array}$ \\
\hline $\begin{array}{l}\text { Anti-intermittence routing } \\
\text { protocol [15] }\end{array}$ & $\begin{array}{l}\text { - Spectrum awareness } \\
\text { - } \text { Route established once work for long time } \\
\text { - } \text { Modified route maintenance algorithm }\end{array}$ & $\begin{array}{l}\text { - Uses pre defined assumptions } \\
\text { parameter }\end{array}$ \\
\hline $\begin{array}{l}\text { ROuting and Spectrum } \\
\text { Allocation (ROSA) [17] }\end{array}$ & $\begin{array}{lll}\text { - } & \text { Distributed dynamic } & \text { Spectrum } \\
& \text { Allocation/Utilization } & \\
\text { - } & \text { High throughput efficiency } \\
\text { - } & \text { Maximizes spectrum utility } \\
\text { - } & \text { Limited bit rate error }\end{array}$ & - Blind trust can lead to harm \\
\hline $\begin{array}{lr}\text { Multipath } & \text { Routing and } \\
\text { distributed } & \text { Spectrum } \\
\text { Access (MRSA) [18] }\end{array}$ & $\begin{array}{l}\text { - } \text { Efforts for disjoint spectru allocation } \\
\text { - } \text { Minimizes contention time and interference. } \\
\text { - High throughput. } \\
\text { - } \text { Effective utilization of resources. } \\
\text { - } \text { primary users } \\
\text { - } \text { Maintains speed of data transmission. } \\
\text { Pailure handling }\end{array}$ & $\begin{array}{l}\text { - Traffic distribution technique is } \\
\text { not that effective }\end{array}$ \\
\hline $\begin{array}{l}\text { Reliable Link Routing } \\
\text { (RLR) [20] }\end{array}$ & $\begin{array}{l}\text { - } \text { Better link stability } \\
\text { - Acceptable level of control packet overhead }\end{array}$ & $\begin{array}{l}\text { - } \text { Scalability problem } \\
\text { - Route recovery mechanism is not } \\
\text { appropriate } \\
\text { - Not suitable for mobile CRN. } \\
\text { - Not suitable for heterogeneous } \\
\text { CRN environment } \\
\end{array}$ \\
\hline $\begin{array}{l}\text { Weighted Hop, spectrum } \\
\text { Aware and sTable routing } \\
\text { (WHAT) [21] }\end{array}$ & $\begin{array}{l}\text { - Evaluates overall quality of a path using } \\
\text { multiple metrics } \\
\text { - High Network throughput }\end{array}$ & - Low cognitive learning capability \\
\hline $\begin{array}{l}\text { TrAffiC aware Routing } \\
\text { protocol (TACR) [23] }\end{array}$ & $\begin{array}{l}\text { - } \text { Low end to end delay } \\
\text { - Reduced packet loss } \\
\text { - High throughput }\end{array}$ & - Implementation is quite complex \\
\hline $\begin{array}{l}\text { IP Spectrum Aware } \\
\text { Geographic routing } \\
\text { ( IPSAG) [24] }\end{array}$ & $\begin{array}{l}\text { - Geographical position based routing } \\
\text { - Adaptable to change in topology. }\end{array}$ & $\begin{array}{l}\text { - Degraded performance in large } \\
\text { CRN } \\
\text { - Control packet overhead is } \\
\text { extremely very high. } \\
\text { - High average end-to-end delay. } \\
\text { - No efficient route recovery } \\
\text { algorithm }\end{array}$ \\
\hline $\begin{array}{l}\text { Gateway Cluster IP } \\
\text { Spectrum Aware } \\
\text { Geographic routing } \\
\text { (GC-IPSAG) [25] }\end{array}$ & $\begin{array}{l}\text { - Geographical location based routing } \\
\text { - Destination position is known by the source. }\end{array}$ & $\begin{array}{l}\text { - Large table size. } \\
\text { - In high mobility CRN } \\
\text { environment very high } \\
\text { delay, control overhead and other } \\
\text { resource consumption }\end{array}$ \\
\hline $\begin{array}{l}\text { Head node based Cluster IP } \\
\text { Spectrum Aware } \\
\text { Geographic routing } \\
\text { (HC-IPSAG) [25] }\end{array}$ & $\begin{array}{l}\text { - Source is fully aware of Destination } \\
\text { position } \\
\text { - Low packet loss }\end{array}$ & - Large table size \\
\hline $\begin{array}{lr}\text { Backup Channel and } \\
\text { Cooperative } \quad \text { Channel }\end{array}$ & $\begin{array}{l}\text { - Better spectrum management. } \\
\text { - Minimizes packet collision. }\end{array}$ & $\begin{array}{l}\text { - Need to maintain a lot of } \\
\text { information }\end{array}$ \\
\hline
\end{tabular}




\begin{tabular}{|c|c|c|}
\hline $\begin{array}{l}\text { Switching } \\
\text { (BCCCS) [26] }\end{array}$ & - Low resource consumption. & \\
\hline $\begin{array}{l}\text { Cognitive Routing Metric } \\
\text { with Improving Capacity } \\
\text { (CRM-IC) [27] }\end{array}$ & $\begin{array}{l}\text { - High network capacity } \\
\text { - High end to end throughput } \\
\text { - } \quad \text { Low transmission completion time }\end{array}$ & $\begin{array}{l}\text { - Vital considerations missing in } \\
\text { routing process }\end{array}$ \\
\hline $\begin{array}{l}\text { Node Disjoint Multi-path } \\
\text { routing scheme based on } \\
\text { AODV } \\
(\text { NDM_AODV) }[28]\end{array}$ & $\begin{array}{l}\text { - Increased network life by routing through } \\
\text { node with higher energy. }\end{array}$ & $\begin{array}{l}\text { - Inefficient with respect to delay } \\
\text { and hop-count }\end{array}$ \\
\hline $\begin{array}{l}\text { New routing metriC and } \\
\text { protocol for Multipath } \\
\text { routing }(\mathrm{NCM})[30]\end{array}$ & $\begin{array}{l}\text { - } \text { Multi hop routing based on non closeness } \\
\text { - Effective use of backup routes } \\
\text { - Suitable for multi-hop CRN environment } \\
\text { where PU are mobile and SU are stationary. }\end{array}$ & $\begin{array}{ll}\text { - } & \text { Spectrum density is not } \\
\text { considered. } \\
\text { - High resource consumption. } \\
\text { - } \begin{array}{l}\text { Suitable only if SU are GPS } \\
\text { enabled. }\end{array}\end{array}$ \\
\hline $\begin{array}{l}\text { Spectrum and Energy } \\
\text { aware Routing (SER) [31] }\end{array}$ & $\begin{array}{l}\text { - High network throughput. } \\
\text { - Increase network life. } \\
\text { - Load balancing. }\end{array}$ & $\begin{array}{l}\text { - Underutilization of spectrum } \\
\text { resources. } \\
\text { - High channel switching causes } \\
\text { high energy consumption. } \\
\text { - Does not consider PU region } \\
\text { - Not suitable for highly mobile } \\
\text { CRN }\end{array}$ \\
\hline $\begin{array}{l}\text { UNITED nodes: cluster } \\
\text { based routing protocol [33] }\end{array}$ & $\begin{array}{l}\text { - } \text { Cluster based routing } \\
\text { - Low latency } \\
\text { - High data throughput } \\
\text { - Effective management for congestion } \\
\text { reduction and link failure }\end{array}$ & $\begin{array}{l}\text { - High routing complexity due to } \\
\text { local \& global synchronization } \\
\text { - May give non optimal path for } \\
\text { nodes in different clusters } \\
\text { - Frequent change in topology } \\
\text { causes critical increase in number } \\
\text { of control packets } \\
\text { - High consumption of network } \\
\text { energy and spectrum }\end{array}$ \\
\hline $\begin{array}{l}\text { Multi-Objective } \\
\text { Reinforcement Learning } \\
\text { based routing (MORL) [34] }\end{array}$ & - Low transmission delay. & $\begin{array}{l}\text { - Long route or may create a loop. } \\
\text { - During low PU activity } \\
\text { transmission delay increases. } \\
\text { - High packet loss rate. }\end{array}$ \\
\hline $\begin{array}{ll}\text { Bio-inspired } & \text { Stability } \\
\text { Routing scheme } & \\
\text { (BioStaR) [35] } & \end{array}$ & $\begin{array}{ll}\text { - } & \text { Effective utilization of spectrum } \\
& \text { opportunity } \\
\text { - } & \text { Low vulnerability towards PU activity } \\
\text { - Low channel switching delay } \\
\text { - Low energy consumption }\end{array}$ & $\begin{array}{l}\text { - } \text { GPS is required } \\
\text { - Low network performance for } \\
\text { highly dynamic mobile CRN. }\end{array}$ \\
\hline $\begin{array}{l}\text { Cognitive AODV } \\
\text { (CAODV) [36] }\end{array}$ & $\begin{array}{l}\text { - } \text { Better path maintenance } \\
\text { - Reduced route cost. } \\
\text { - Support dynamic CRN } \\
\text { - Selects shortest path }\end{array}$ & $\begin{array}{l}\text { - } \text { High resource consumption. } \\
\text { - Route recovery increases control } \\
\text { overhead }\end{array}$ \\
\hline $\begin{array}{l}\text { Dual Diversity Cognitive } \\
\text { Ad hoc Routing Protocol } \\
\text { (D2CARP) [37] }\end{array}$ & $\begin{array}{l}\text { - Effectively tackles path and spectrum } \\
\text { diversity } \\
\text { - Better packet delivery ratio, overhead, } \\
\text { delay, hop-count }\end{array}$ & $\begin{array}{l}\text { - Requires RREP to be broadcasted } \\
\text { to source } \\
\text { - } \quad \text { High resource consumption } \\
\text { - } \quad \text { Large routing tables }\end{array}$ \\
\hline $\begin{array}{l}\text { MultihoP and multiflow } \\
\text { mobile adhoc cognitive } \\
\text { based joint stable routing } \\
\text { and Channel Assignment } \\
\text { (MP-JSRCA) [38] }\end{array}$ & $\begin{array}{l}\text { - Check for Location based spectrum } \\
\text { availability } \\
\text { - Route stability routing } \\
\text { - Low power consumption }\end{array}$ & $\begin{array}{l}\text { - Performs better only for smal } \\
\text { sized network }\end{array}$ \\
\hline $\begin{array}{l}\text { PRP-HOL: Performance } \\
\text { Modeling and Analysis of } \\
\text { the Delay Aware Routing } \\
\text { Metric in Cognitive Radio } \\
\text { Ad Hoc Networks [39] }\end{array}$ & $\begin{array}{l}\text { - Delay aware routing based on queuing } \\
\text { model } \\
\text { - Better spectrum management } \\
\text { - High performance when number of SU is } \\
\text { large }\end{array}$ & $\begin{array}{l}\text { - Not suitable for a network with } \\
\text { small number of SUs }\end{array}$ \\
\hline $\begin{array}{l}\text { PRP-EOL: Performance } \\
\text { Modeling and Analysis of } \\
\text { the Delay Aware Routing }\end{array}$ & $\begin{array}{l}\text { - Delay aware routing for less SUs based on } \\
\text { queuing model } \\
\text { - Better results when SU are less n low traffic }\end{array}$ & $\begin{array}{l}\text { - As number of SU increases delay } \\
\text { starts increasing leading to } \\
\text { degradation in network }\end{array}$ \\
\hline
\end{tabular}




\begin{tabular}{|l|l|c|}
\hline $\begin{array}{l}\text { Metric in Cognitive Radio } \\
\text { Ad Hoc Networks [39] }\end{array}$ & & performance \\
\hline LAUNCH: A Location- & $\bullet$ Location based routing protocol & $\bullet$ Ignorance towards \\
aided routing protocol for & $\bullet$ Good performance evaluation analysis & consumption \\
Cognitive Radio & $\bullet$ Minimize channel switching delay. & \\
Networks[40] & & \\
\hline
\end{tabular}

\section{Problem Identification}

The literature survey shows that to ensure the effectiveness of a routing protocol for $\mathrm{CRN}$, a number of parameters need to be considered and their collaborative effectiveness and efficiency has to be ensured. Thus the overall problem of CRN routing protocol design can be considered as an issue/task relating to multi-parameter optimization wherein all QoS parameters are effectively tackled.

\section{The Objective}

To design a routing protocol that effectively tackles all QoS parameters.

\section{The Proposal}

One of the elegant ways to combine all vital QoS parameters in a routing protocol for CRN can be in the form of a Knowledge Based System that handles a variety of situations in an effective manner using a rule-based system. Since the required actions in a protocol are based upon the range of values of input parameters therefore under the circumstances a fuzzy rule based expert system in which the required action is inferred depending upon the range of values of various input parameters shall be a good choice. Therefore, this paper proposes a novel fuzzy logic based routing strategy for CRNs with a view to optimize the performance of the network.

\subsection{The Proposed Scheme}

The proposed routing scheme is based on Fuzzy Logic based expert system. So, before taking up the proposal let us take a brief account of Fuzzy Logic based Expert system commonly referred to as Fuzzy Expert System.

\subsubsection{Fuzzy Expert System (FES)}

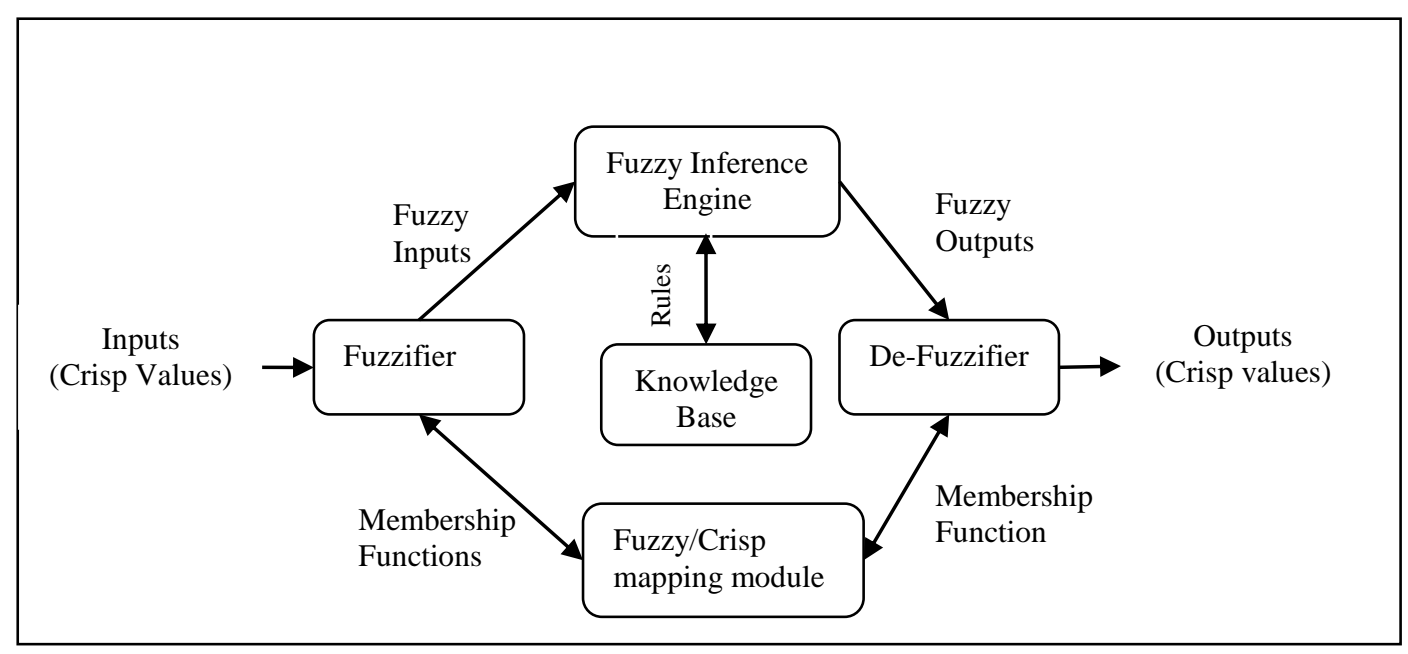

Figure 1. Block Diagram of Fuzzy Expert System (FES) 
The description of basic blocks is as follows:

The process begins with the reading of numeric values of input parameters. These crisp values are fed to the Fuzzifier module for fuzzification.

- Fuzzifier Module: - This module transforms the crisp inputs into linguistic variables and there corresponding memberships. Linguistic variables and their memberships are defined in accordance with the domain of the input variables. The detailed description of the linguistic variables and their corresponding membership is resident in Data Base of membership functions.

- Fuzzy/Crisp mapping module:- This module contains the mathematical details for converting a crisp value to its corresponding fuzzy set and associated membership value and vice versa.

- Knowledge Base: - This module contains a library of conditional rules in 'IFTHEN' form. The inference engine refers to this library and selects the lists of rules to be fired. The fuzzy output of fired rules is sent to the defuzzifier module.

- Inference Engine: - It refers to the knowledge base and selects the relevant rules to be fired. The selected rules are placed in the conflict set and fired one by one. The inference engine used in our case is that of mamdani-type.

- Defuzzification Module: - This module receives the fuzzy input from the inference engine and converts in into the corresponding crisp value using any of the chosen defuzzification method. The defuzzification method used in our case is Centre of Gravity (CoG).

\subsection{Protocol design through FES}

Figure 2 shows the block diagram of proposed routing scheme based upon 4 input parameters: Transmission Power, Delay, Hop count and Throughput. All these parameters are provided as input to the FES that selects the optimal path as the output.

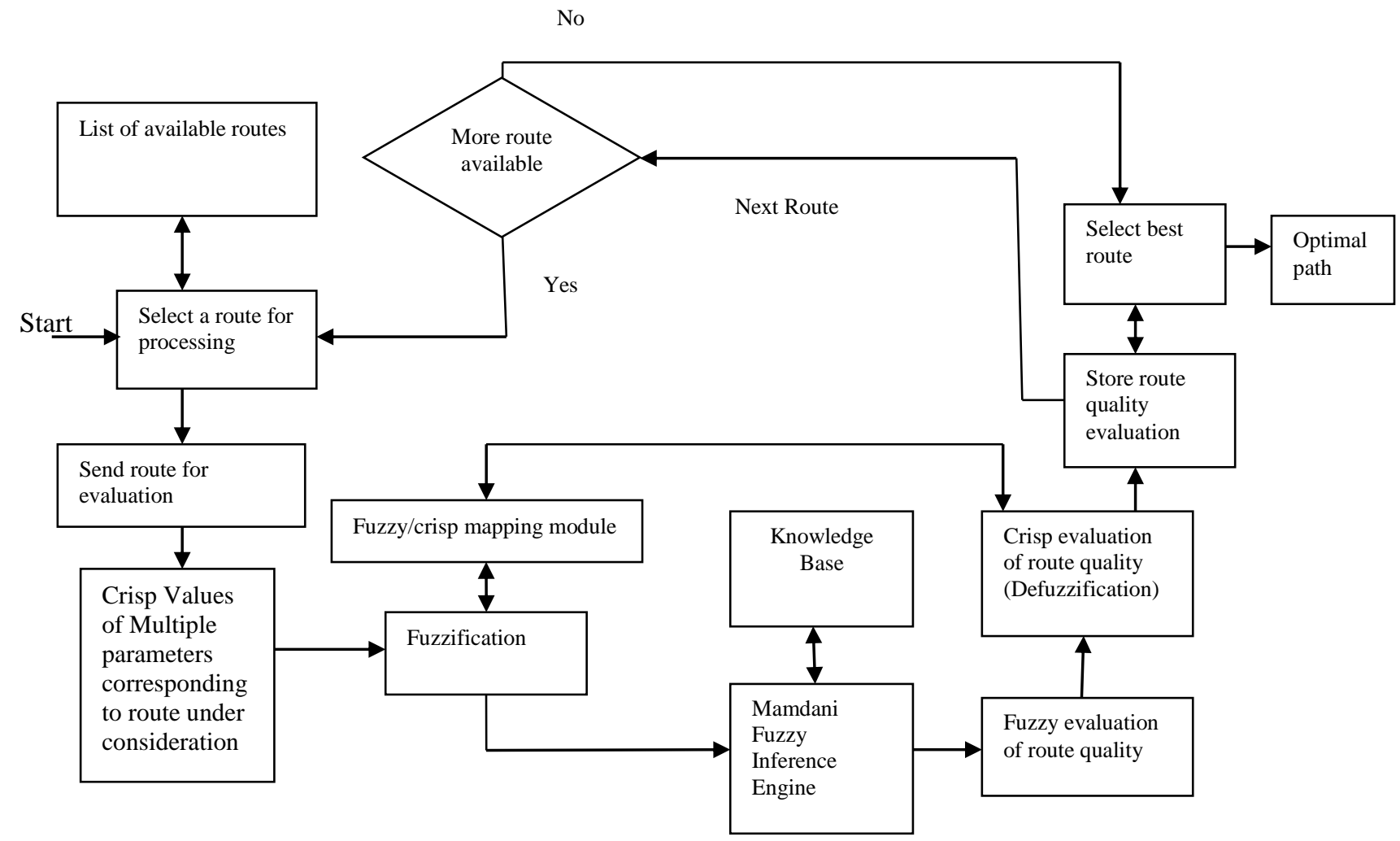

Figure 2. FES for Proposed Protocol 
The working of FES is as follows:

- Initially all the possible routes from source to destination are calculated and stored in list of available routes.

- A route is selected for processing and numerical value of multiple QoS parameters is taken. The parameters taken in our protocol are transmission power, delay, throughput and hop count.

- Crisp value of multiple QoS parameters is provided to fuzzification module where crisp values are mapped to fuzzy sets along with associated membership values using fuzzy/crisp mapping module.

- These fuzzy values of QoS parameters are provided to mamdani fuzzy inference engine. Inference engine refers to the knowledge base and selects the relevant rules to be fired. The selected rules are placed in the conflict set and fired.

- Fuzzy value of route quality is provided to defuzzification module. This module maps fuzzy value of route quality on crisp value using fuzzy/crisp mapping module.

- This crisp value of route quality is stored in store route quality evaluation module for comparison with other route's quality.

- This process repeats until all the available routes are processed. When all the routes are processed, best route is selected by select best route module using the crisp values of route quality stored in store route quality evaluation module and results into the optimal path.

\subsubsection{Inputs to FES}

To compute the optimal route FES uses the following input parameters:

5.2.1.1. Transmission Power: It is the total Transmission Power required to forward data from source to destination. Every transmission of data packet decrements the available residual power of the sending / forwarding. The amount of energy required for transmission $[42,43,44]$ of a fixed size packet is given by the following equation

$$
\mathrm{E}_{\mathrm{t}}=\mathrm{r}^{\alpha}+\mathrm{C}_{\mathrm{e}}
$$

Where, $r$ is the transmission range of a node. $\alpha$ is constant which is either 2 or 4 (depending on the behaviour of environment whether it is obstacle free or not)

$\mathrm{C}_{\mathrm{e}}$ : Constant energy dissipated in transmitter circuitry

$\mathrm{E}_{\mathrm{t}}$ : Energy consumption at transmitter side

The value of $\alpha=4$ and the $C_{e}=108$. These values $[43,44]$ are taken in arbitrary units and can be converted into any given units by using an applicable multiplication factor.

5.2.1.2. Delay: It is defined as the time needed to reach the data packets from source to destination. Total delay of the path is computed by transmission delay, queuing delay, switching and propagation delay [45].

$($ Total Delay) Path $\mathrm{i}=($ Transmission Delay) Path $\mathrm{i}+($ Queuing Delay $)$ Path $\mathrm{i}+($ Switching delay) Path i + (Propagation Delay) Path i

- Transmission Delay: - Time period required in pushing all bits in a packet on the transmission medium in use.

$$
\mathrm{d}=\mathrm{S} / \mathrm{N}
$$

where $\mathrm{S}$ is the size of data packet and $\mathrm{N}$ is the number of bits

- Queuing Delay:-Time period for which a node waits in a queue to get a particular frequency band. 
(Queuing Delay At time $\mathrm{t})_{\text {Path } \mathrm{i}}=\operatorname{Max}_{(\mathrm{k}=\mathrm{S} \text { to } \mathrm{D}) \text { in path } \mathrm{i}}$ ( Time instant when node $\mathrm{k}$ will be available) ${ }_{k}$ - Current time $\mathrm{t}_{\mathrm{t}}$

- Switching Delay: - This delay occurs when a node changes its frequency band either from higher to lower or lower to higher. Switching delay is significantly smaller delay in micro second or nano seconds.

- Propagation Delay: - The time required for a bit to traverse to the trajectory path of the transmission medium.

$$
(\text { Propagation Delay })_{\text {Path }}=(\text { Total Distance }) \text { Path } i / \text { Speed of Light }
$$

5.2.1.3. Throughput: It indicates the data rate or speed of the received data in bits per seconds or data packets per second. Data rate may differ in different nodes in a particular path. This rate varies between different nodes in a particular path hence minimum data rate is considered as throughput for a path $\mathrm{i}$.

$$
[\text { Throughput }]_{\text {Path } \mathrm{i}}=\operatorname{Min}_{(\mathrm{k}=\mathrm{S} \text { to } \mathrm{D}) \text { in Path i }}\left([\text { Throughput }]_{\mathrm{k}}\right)
$$

5.2.1.4. Hop Count: It indicates the total number of intermediate nodes in a particular path i.

$$
\text { Hop count }=\sum_{j=\text { source }}^{\text {destination }} \text { node } \mathrm{j}_{\mathrm{j}} \text { for a selected path } \mathrm{i} .
$$

\subsubsection{Fuzzification}

All the input parameters are crisp values and these crisp values are provided as input to the FES. The Fuzzification process converts the crisp data into fuzzy set by using the membership functions $[46,47,48]$.

5.2.2.1. Membership functions for FES input: To find the optimal path from source to destination all the above mentioned input parameters are combined Using mamdani based fuzzy expert system. The input variables i.e. transmission power, delay, throughput are associated with three fuzzy sets namely low, medium and high with their membership functions as shown in the Figure 3, Figure 4 and Figure 5 respectively. The input variables hop count is associated with two fuzzy sets namely low and high with their membership functions as shown in the Figure 6.

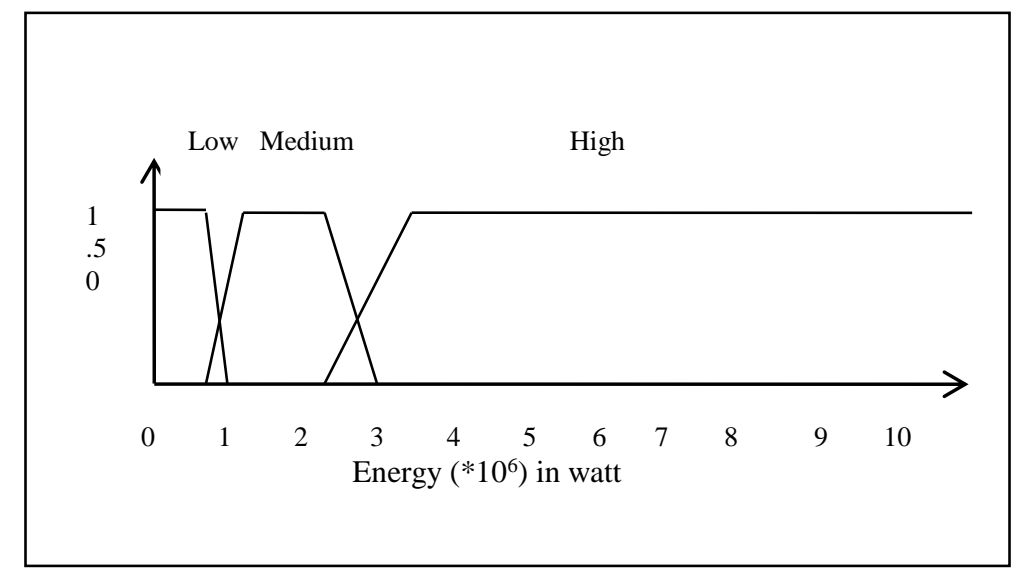

Figure 3. Membership Function for Transmission Power 


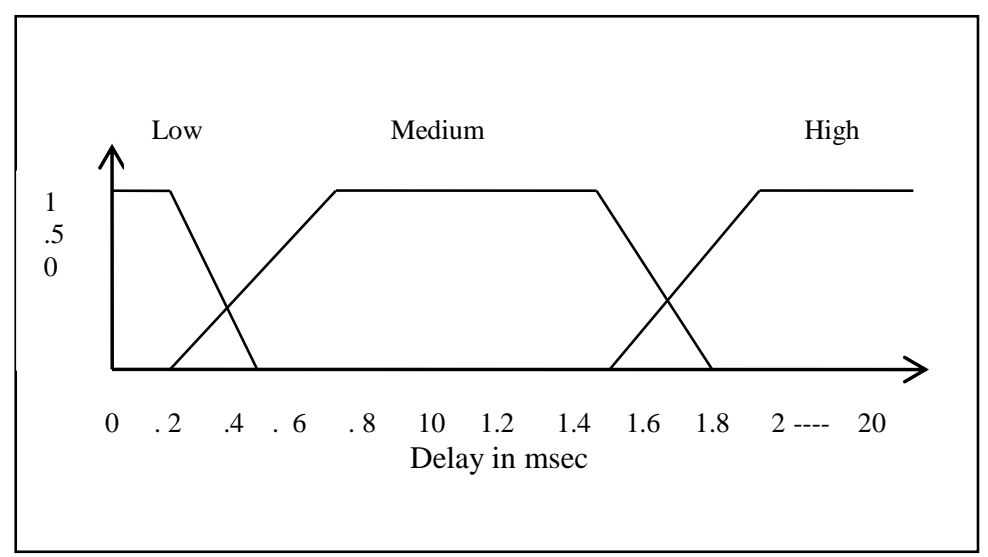

Figure 4. Membership Function for Delay

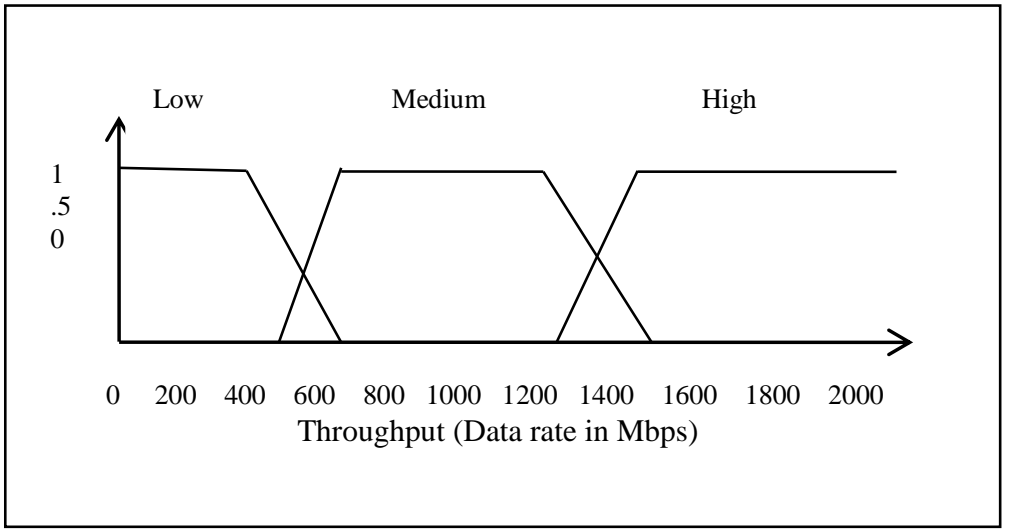

Figure 5. Membership Function for Throughput

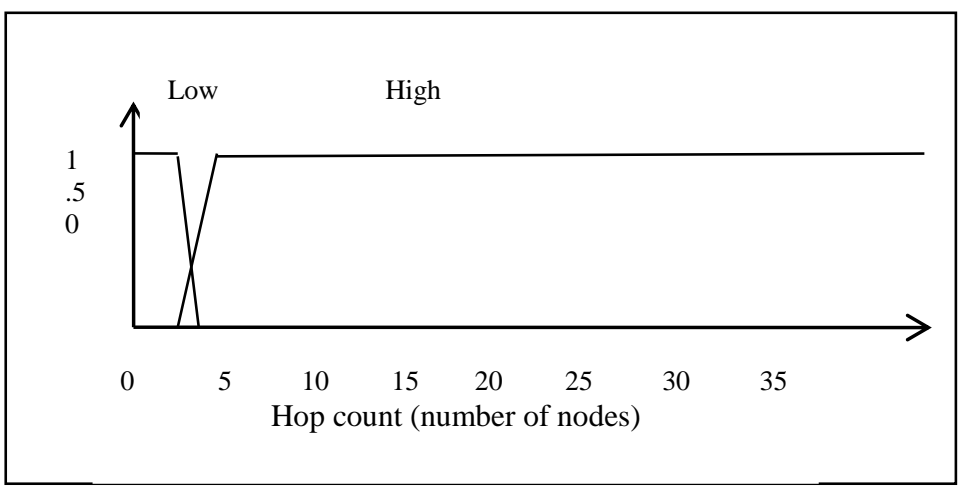

Figure 6. Membership Function for Hop Count

5.2.2.2. Membership functions: The membership function details of various fuzzy sets related to different input parameters is as follow:

1. Transmission Power $\left(\mathrm{TP}^{*} 10^{6}\right)$ in watt

Low $(\mathrm{TP})=\left\{\begin{array}{lr}1 & 0 \leq \mathrm{TP} \leq 0.8 \\ (1-\mathrm{TP}) / 0.2 & 0.8 \leq \mathrm{TP} \leq 1 \\ 0 & \text { otherwise }\end{array}\right.$ 


$$
\text { Medium }(\mathrm{TP})=\left\{\begin{array}{cc}
0 & \mathrm{TP} \leq 0.8 \& \mathrm{TP} \geq 3.25 \\
(\mathrm{TP}-0.8) / 0.2 & 0.8 \leq \mathrm{TP} \leq 1.0 \\
1 & 1.0 \leq \mathrm{TP} \leq 2.25 \\
(3-\mathrm{TP}) / 0.75 & 2.25 \leq \mathrm{TP} \leq 3
\end{array}\right.
$$

$$
\operatorname{High}(\mathrm{TP})=\left\{\begin{array}{lr}
0 & 0 \leq \mathrm{TP} \leq 2.25 \\
\mathrm{TP}-2.25 & 2.25 \leq \mathrm{TP} \leq 3.25 \\
1 & 3.25 \leq \mathrm{TP} \leq 10
\end{array}\right.
$$

2. Delay (D) in milliseconds

$$
\begin{aligned}
& \text { Low }(D)= \begin{cases}1 & \multicolumn{1}{c}{0 \leq \mathrm{D} \leq 0.2} \\
(0.5-\mathrm{D}) / 0.3 & 0.2 \leq \mathrm{D} \leq 0.5 \\
0 & \text { otherwise }\end{cases} \\
& \text { Medium }(\mathrm{D})= \begin{cases}0 & \mathrm{D} \leq 0.2 \& \mathrm{D} \geq 1.8 \\
(\mathrm{D}-0.2) / 0.5 & 0.2 \leq \mathrm{D} \leq 0.7 \\
1 & 0.7 \leq \mathrm{D} \leq 1.5 \\
(1.8-\mathrm{D}) / 0.3 & 1.5 \leq \mathrm{D} \leq 1.8\end{cases} \\
& \operatorname{High}(\mathrm{D})= \begin{cases}0 & 0 \leq \mathrm{D} \leq 1.5 \\
(\mathrm{D}-1.5) / 0.5 & 1.5 \leq \mathrm{D} \leq 2 \\
1 & 2 \leq \mathrm{D} \leq 20\end{cases}
\end{aligned}
$$

3. Throughput (TH) in Mbps

$$
\begin{aligned}
& \text { Low }(\mathrm{TH})=\left\{\begin{array}{lc}
1 & 0 \leq \mathrm{TH} \leq 450 \\
(650-\mathrm{TH}) / 200 & \begin{array}{c}
450 \leq \mathrm{TH} \leq 650 \\
\text { otherwise }
\end{array}
\end{array}\right. \\
& \text { Medium }(\mathrm{TH})= \begin{cases}0 & \mathrm{TH} \leq 500 \& \mathrm{TH} \geq 1500 \\
(\mathrm{TH}-500) / 150 & 500 \leq \mathrm{TH} \leq 650 \\
1 & 650 \leq \mathrm{TH} \leq 1300 \\
(1500-\mathrm{TH}) / 200 & 1300 \leq \mathrm{TH} \leq 1500\end{cases} \\
& \text { High }(\mathrm{TH})= \begin{cases}0 & 0 \leq \mathrm{TH} \leq 1300 \\
0 & 1300 \leq \mathrm{TH} \leq 1500 \\
(\mathrm{TH}-1300) / 200 & 1500 \leq \mathrm{TH} \leq 2000 \\
1 & \end{cases}
\end{aligned}
$$

\section{Hop Count $(\mathrm{N})$}

Low $(\mathrm{N})= \begin{cases}1 & 0 \leq \mathrm{N} \leq 3 \\ 4-\mathrm{N} & 3 \leq \mathrm{N} \leq 4 \\ 0 & \text { otherwise }\end{cases}$
High $(\mathrm{N})= \begin{cases}0 & 0 \leq \mathrm{N} \leq 3 \\ 2 * \mathrm{~N}-3 & 3 \leq \mathrm{N} \leq 4 \\ 1 & 4 \leq \mathrm{N} \leq 100\end{cases}$


5.2.3. Rule Base for FES: The rule base for expert system has been designed with following factors in consideration:

- In CRN the nodes are mobile and network is Ad Hoc, therefore battery power saving is an vital issue, which if not tackled properly, can lead to generation of selfish nodes and packet dropping making the network unreliable. Under the circumstances, a quality path from source to destination must have low transmission power required to transmit a data packet should and delay should also be low.

- Throughput is next vital factor but certainly after delay and transmission power. If the delay and transmission power are high for a particular path then the impact of throughput can be ignored to choose other path with lower delay and transmission power.

- Consideration of hop count is of least importance in comparison to transmission power, delay and throughput. If a path is having low delay and low transmission power requirement then hop count factor can be ignored. On the same levels of delay, transmission power and throughput a path with lower hop count shall be preferred over a path with higher hop count.

Table 2. Rule Base of the Fuzzy Expert System

\begin{tabular}{|c|c|c|c|c|}
\hline IF & IF & IF & IF & THEN \\
\hline $\begin{array}{c}\text { Transmission } \\
\text { power }\end{array}$ & Delay & Throughput & Hop Count & Output \\
\hline Low & Low & & Low & Best \\
\hline Low & Low & & High & Best \\
\hline Med & Low & & Low & Best \\
\hline Med & Low & & High & Best \\
\hline High & Low & High & Low & Best \\
\hline High & Low & High & High & Best \\
\hline High & Low & Not high & Low & Best \\
\hline High & Low & Not high & High & Best \\
\hline Low & Mid & & Low & Moderate \\
\hline Low & Mid & Not low & High & Moderate \\
\hline Mid & Mid & Not low & Low & Moderate \\
\hline Mid & Mid & Not low & High & Moderate \\
\hline High & Mid & Not low & Low & Moderate \\
\hline High & Mid & Not low & High & Moderate \\
\hline Low & High & High & Low & Moderate \\
\hline Low & High & High & High & Moderate \\
\hline Mid & High & High & Low & Moderate \\
\hline Mid & High & High & High & Moderate \\
\hline High & High & & Low & Moderate \\
\hline High & High & & High & Moderate \\
\hline Low & Mid & Not low & High & Poor \\
\hline Mid & Mid & Not Low & Low & Poor \\
\hline Mid & Mid & Low & High & Poor \\
\hline High & Mid & Low & Low & Poor \\
\hline High & Mid & Low & High & Poor \\
\hline Low & High & Not high & Low & Poor \\
\hline Low & High & Not high & High & Poor \\
\hline Mid & High & Not high & Low & Poor \\
\hline
\end{tabular}


5.2.4. Defuzzification: Defuzzification is the process of computing crisp results from fuzzy inputs. The literature contains many methods for the defuzzification process such as Centre of Gravity $(\mathrm{CoG})$, Centre of area (CoA), first of maxima, middle of maxima etc. Here, FES has used CoG method with output as

$$
\frac{\sum_{i=1, n} m i A i}{\sum_{i=1, n} A i}
$$

Where $n$ is the number of rules fired. $A_{i}$ is the output fuzzy set corresponding to $i^{\text {th }}$ fired rule and $\mathrm{m}_{\mathrm{i}}$ is membership corresponding to $\mathrm{A}_{\mathrm{i}}$.

5.2.4.1. Membership Function for FES Output: The output variable of FES is defined as optimality of the route. The semantic variable for output is characterized as $\{\mathrm{T}$ (output) $\}=\{[$ Poor, Moderate, Best $]\}$. Figure 7 shows that optimality of a path lies between 0 to 1 .

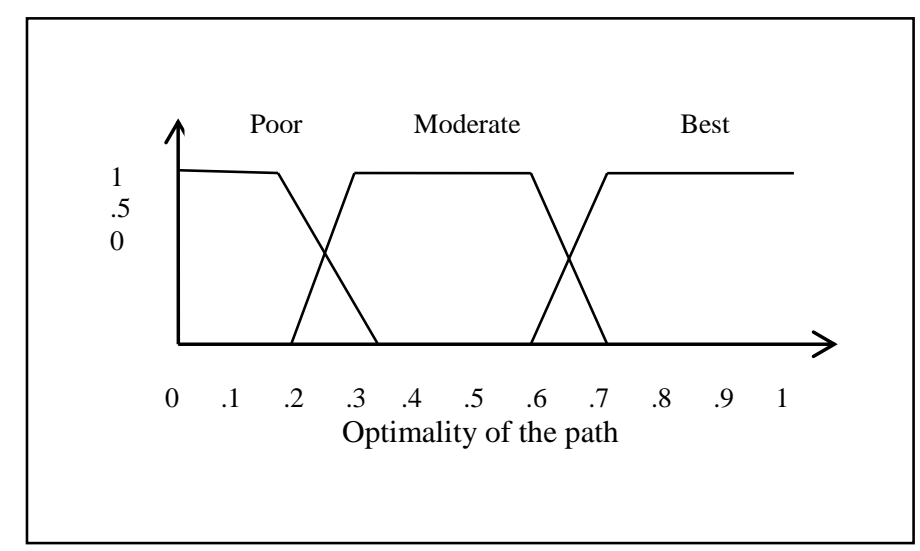

Figure 7. Membership Function for Output of FES

\subsubsection{Equations for fuzzification of output (optimality of path) in FES}

The equations which are used for fuzzification that characterize the membership functions are as follows:-

- Optimality of Path (OP)

$$
\begin{gathered}
\text { Poor }(\mathrm{OP})=\left\{\begin{array}{lc}
1 & 0 \leq \mathrm{OP} \leq 0.18 \\
(.36-\mathrm{OP}) / 0.18 & 0.18 \leq \mathrm{OP} \leq 0.36 \\
0 & \text { Otherwise }
\end{array}\right. \\
\text { Moderate }(\mathrm{OP})=\left\{\begin{array}{lr}
0 & \mathrm{OP} \leq 0.2 \& \mathrm{OP} \geq 0.7 \\
(\mathrm{OP}-0.2) / 0.1 & 0.2 \leq \mathrm{OP} \leq 0.3 \\
1 & 0.3 \leq \mathrm{OP} \leq 0.57 \\
(0.7-\mathrm{OP}) / 0.13 & 0.57 \leq \mathrm{OP} \leq 0.7
\end{array}\right.
\end{gathered}
$$

$$
\text { Best }(\mathrm{OP})= \begin{cases}0 & 0 \leq \mathrm{OP} \leq 0.6 \\ (\mathrm{OP}-0.6) / 0.09 & 0.6 \leq \mathrm{OP} \leq 0.69 \\ 1 & 0.69 \leq \mathrm{OP} \leq 1\end{cases}
$$




\section{Experimental Setup}

The proposed QoS based routing protocol was implemented in MATLAB-9.0 and compared with shortest spectrum aware routing protocol exploiting CRN capabilities. Various performance metrics have been used to evaluate and compare the performance of proposed routing strategy for $\mathrm{CRN}$ as discussed below:

6.1. Metrics used: Following are the performance metrics:-

- Packet delivery ratio (PDR): It is the ratio of number of data packets delivered to a particular destination. Greater value of PDR indicates better performance of a protocol.

$\mathrm{PDR}=\sum$ No. of packets received $/ \sum$ No. of packets sent

- Transmission power: It is the total power/transmission power consumption to forward data from source to destination. The path having minimum required transmission power indicates that nodes are less distant comparatively.

- Delay: It is defined as the time needed to reach a data unit from source to destination. It has 4 constituent propagation delay, queuing delay, switching delay and transmission delay.

- Hop Count: It is defined as the number of intermediate hops from source to destination in the selected path.

- Throughput: It indicates the data rate or speed of the received data in bits per seconds or data packets per second. Data rate may differ in different nodes in a particular path.

6.2. Set-up Parameters: The values of various set up parameters used in simulation process has been given in Table-3.

Table 3. Set-Up Parameters

\begin{tabular}{|l|l|}
\hline Area & $1500^{*} 1500$ \\
\hline Transmission Range & 400 \\
\hline Nodes(SU) & $24-36 \quad$ Step size 6$)$ \\
\hline Nodes (PU) & 16 \\
\hline position of SUs & Random \\
\hline position of Pus & Fixed \\
\hline max velocity & $416 \mathrm{~m} / \mathrm{sec}$ \\
\hline pause time & 0 sec \\
\hline Data rate (our-actual) & $2 \mathrm{Mbps}(\mathrm{PU}),(0.5-1.5 \mathrm{Mbps})$ \\
\hline No of iteration & 25 \\
\hline Source & Chosen randomly from SU \\
\hline Destination & Chosen randomly from SU \\
\hline No of channels per user/node: & 4 \\
\hline Simulation Time for 1 iteration & 20 sec \\
\hline Mobility Model & Random walk \\
\hline Number of Packets sent & 130 \\
\hline
\end{tabular}


6.3. Simulation Region: Snapshot of the simulation region is shown in the figure 8 . Nodes in blue colour are SU nodes which are randomly placed and also move randomly in the region. Nodes in red colour are PU nodes which are fixed. Green line in the snapshot indicates shortest spectrum aware path from source to destination and yellow line indicate the path obtained from proposed QoS based protocol. In the given snapshot node 22 is the source and node 43 is the destination.

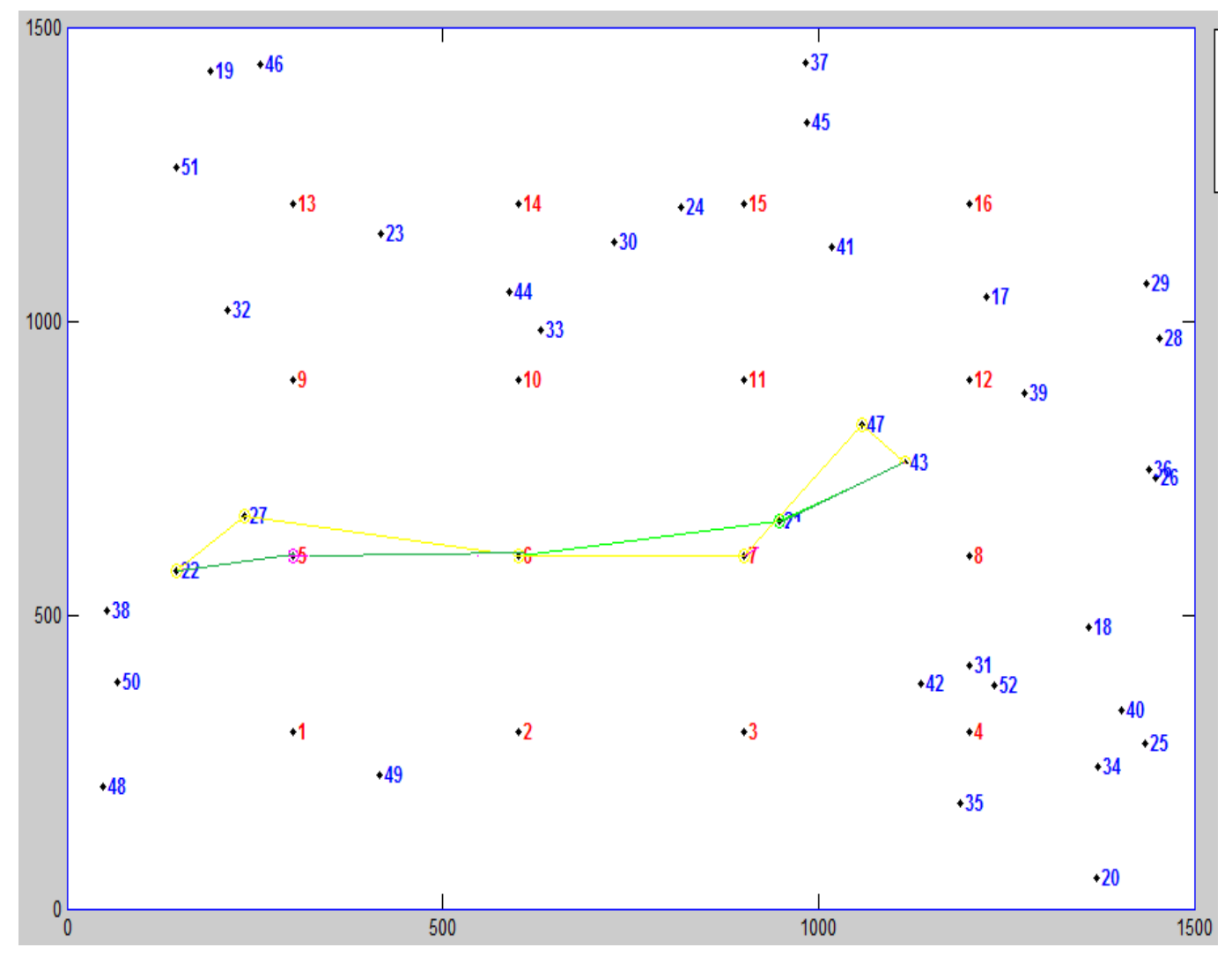

\section{Figure 8. Simulation Region where Source=22, Destination=43 where Yellow Path is the Path and Green is Shortest Spectrum Aware Path}

6.4. Algorithm: The algorithm used to evaluate the performance of the network in terms of above described performance metrics is given below. Before taking up the algorithm as such, let us describe the details of execution process.

Execution Process: There are 16 nodes placed at fixed locations in the simulation region; each PU node has 4 channels. 25 iterations are performed by increasing the concentrations of SUs from 24 to 36 with a step size of 6 . Multiple iterations are performed to find the efficiency of the system with different pair of source and destination. Initially all the nodes are deployed randomly and all the QoS parameters (hop count, PDR, Reach ability and End to end delay are initialized as 0 and after that multiple iterations execute on different source to destination pair to find the possible paths and all the QoS parameters are computed for every path and after many iterations average of all the iterations is computed for all QoS parameter. These crisp values of QoS parameters are provided as input to FES to find the optimal path. 


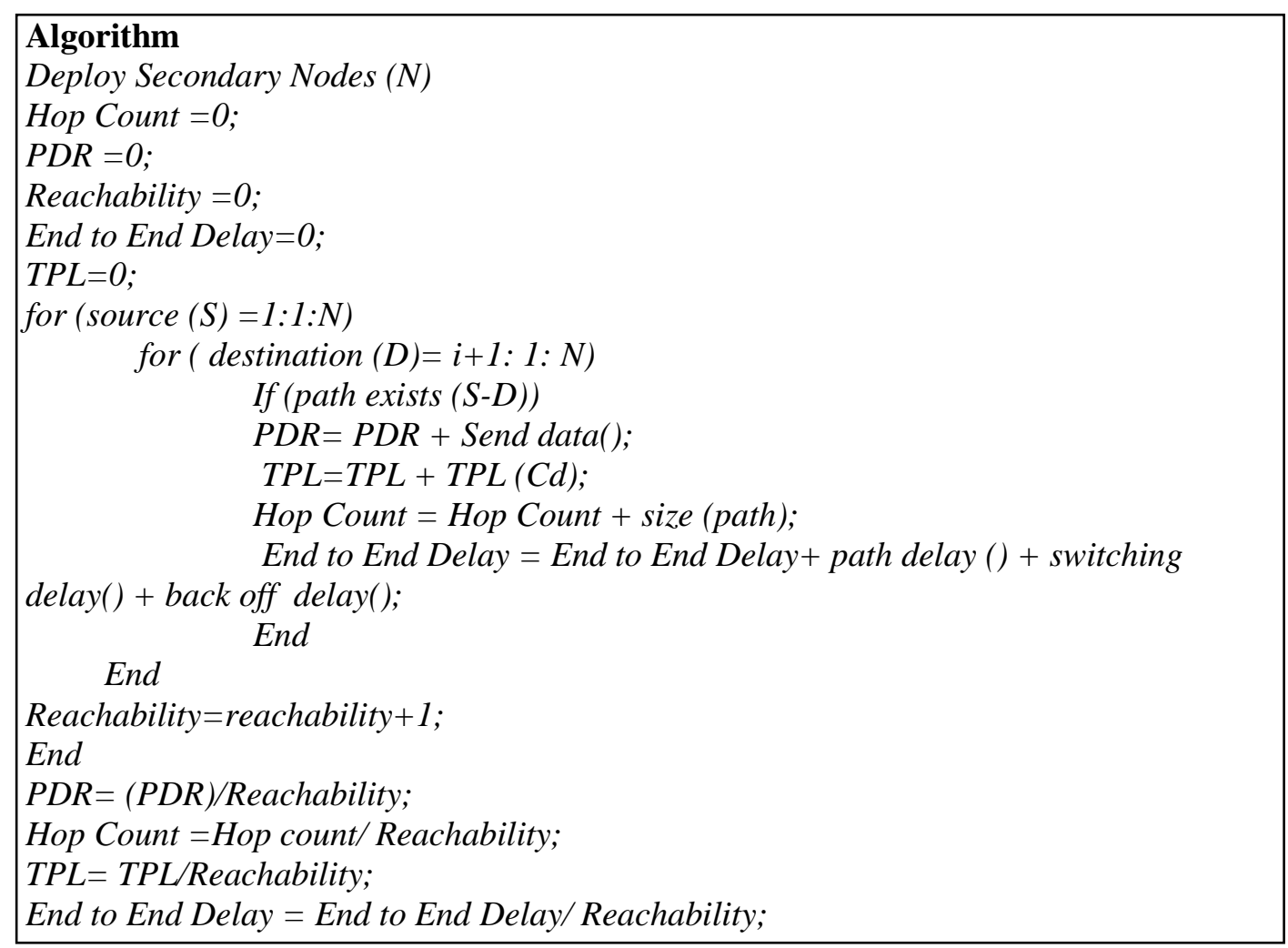

\section{Results}

Impact of increase in concentration of SUs on different QoS parameters of following protocols is shown and discussed below:

- Proposed routing protocol

- Shortest spectrum aware routing protocol

7.1. Average PDR Comparison: Figure 9 shows the impact on the value of PDR with the increase in concentration of SUs.

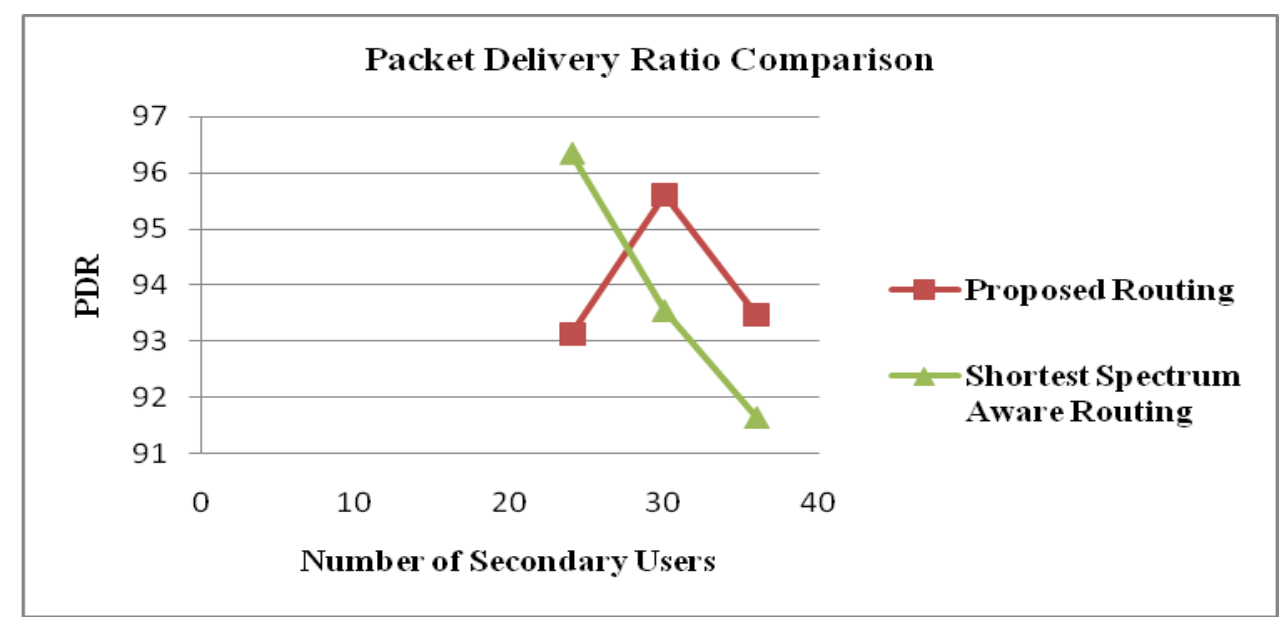

Figure 9. Average PDR Comparisons

Inference: With the increase in the concentration of SUs the PDR of shortest path routing 
degrades while that our protocol upgrades. Thus, the proposed protocol is more suitable for an environment with larger number of secondary users.

7.2. Transmission power Comparison: Figure 10 shows the impact on the value of Transmission power with the increase in concentration of SUs.

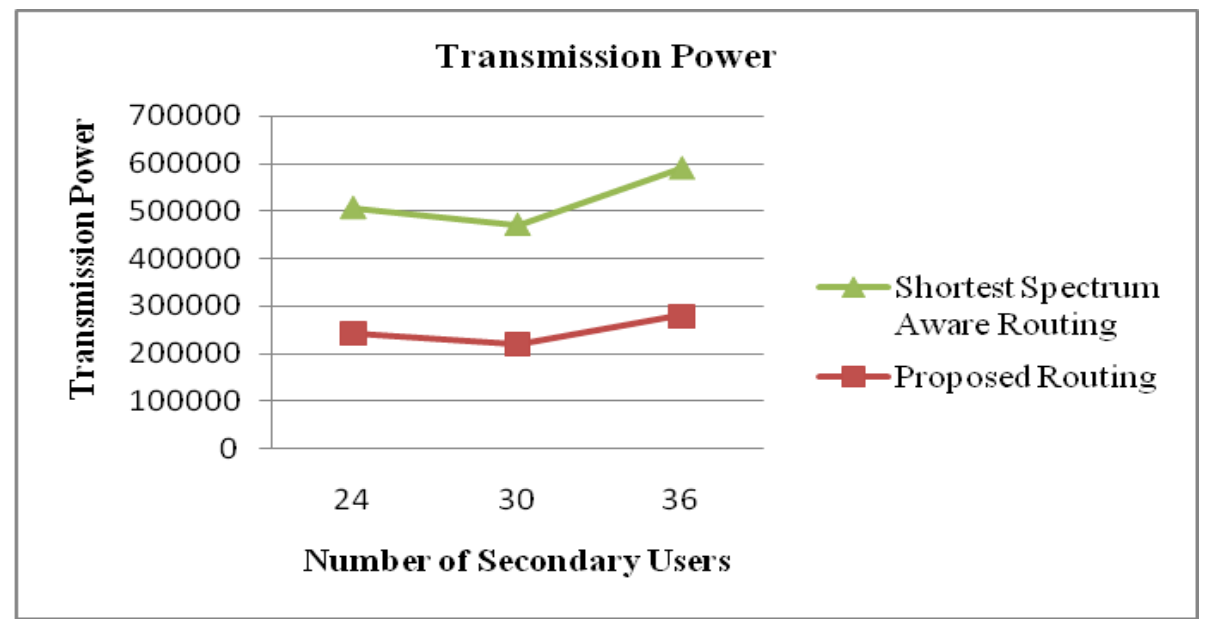

Figure 10. Average Transmission Power (in watt) Comparison

Inference: In all the cases, the proposed protocol outperforms the SSAR.

7.3. Average Hop Count Comparison: Impact on the value of hop count with the increase in concentration of SUs is shown in the figure.

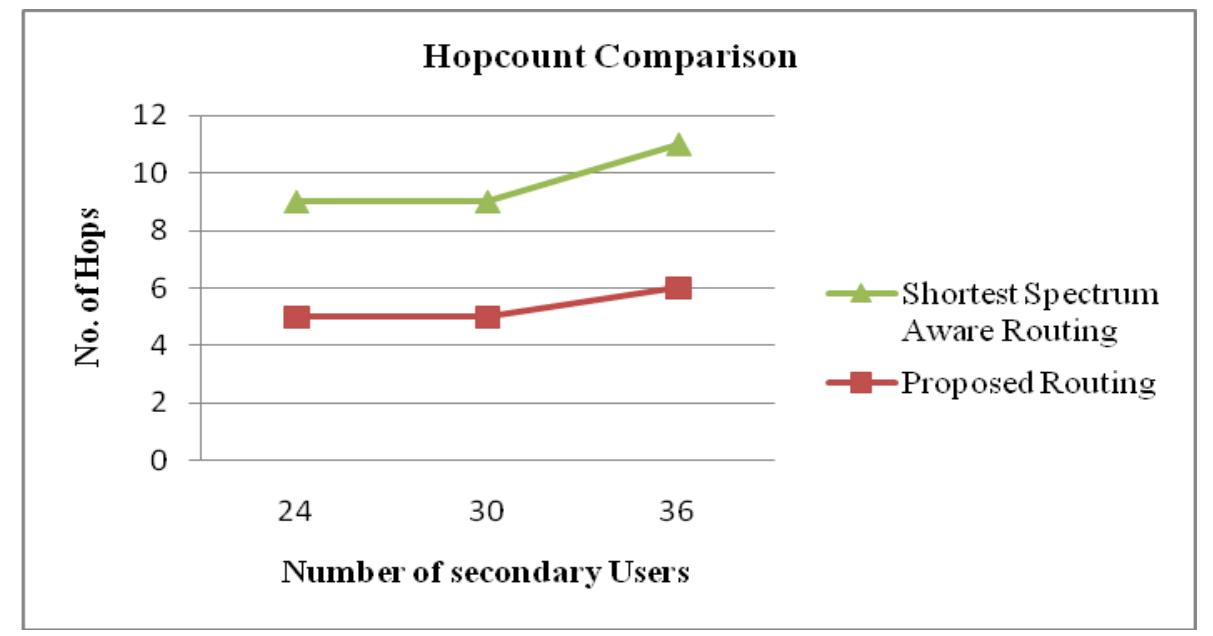

Figure 11. Average Hop Count Comparisons

Inference: Hop count is more for the path obtained through optimal path obtained by proposed routing protocol in comparison to SSAR leading to lower transmission power consumption.

7.4 Average Delay Comparison: Impact on the value of delay with the increase in concentration of SUs is shown in the figure. 


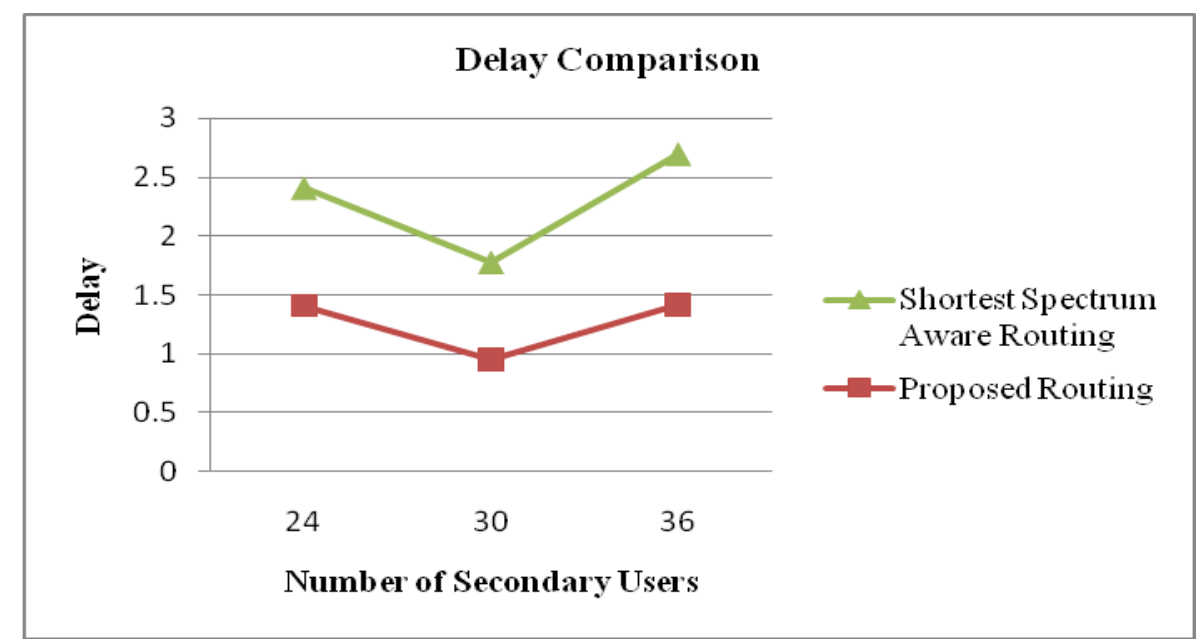

Figure 12. Average Delay (in millisecond) Comparisons

Inference: The average delay is more in case of proposed protocol than SSAR because of larger hop count.

7.5 Average Throughput Comparison: Impact on the value of throughput with the increase in concentration of SUs.

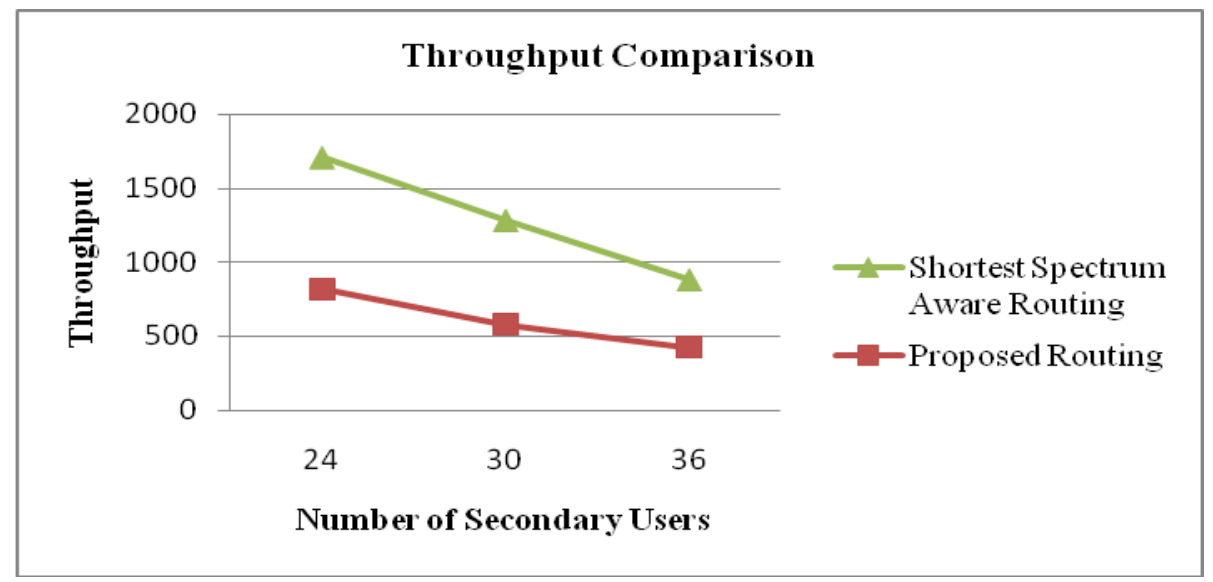

Figure 13. Average Throughput Comparisons

Inference: Throughput is slightly lesser in case of proposed protocol than SSAR.

\section{Conclusion}

The proposed QoS based routing protocol is an effort to find an optimal path for communication. The following were inferences drawn after simulation:

The proposed protocol uses lesser transmission power by using more hop count, thereby saving a lot of battery power. The increased hop count results in higher delay. In case of PDR, the proposed protocol outperforms SSAR as SU concentration increases. Table 4 summarizes the results. 
Table 4. QoS Parameter Comparison

\begin{tabular}{|c|c|c|}
\hline Protocols $\rightarrow$ & $\begin{array}{c}\text { Shortest Spectrum } \\
\text { Aware Routing }\end{array}$ & $\begin{array}{c}\text { Proposed } \\
\text { Routing }\end{array}$ \\
\hline Parameters $\downarrow$ & $\begin{array}{c}\text { Better at lower SU } \\
\text { levels. }\end{array}$ & $\begin{array}{c}\text { Better at higher } \\
\text { SU levels }\end{array}$ \\
\hline $\begin{array}{c}\text { Transmission } \\
\text { power }\end{array}$ & Higher & Lower \\
\hline Hop Count & Lower & High \\
\hline Delay & Low & Slightly More \\
\hline Throughput & High & Slightly High \\
\hline
\end{tabular}

\section{References}

[1] Federal Communication Commission survey-2003 https://apps.fcc.gov/edocs_public/attachmatch/DOC312420A1.pdf.

[2] W. Akyildiz, Y. Lee and K. Chowdhury, "CRAHNs: cognitive radio ad hoc networks", Published in the International Journal of Ad Hoc Networks (Elsevier), vol. 6, (2009), pp. 810-836.

[3] Y. Liang, K. Cheng and G. Chen, "Cognitive Radio Networking and communications: An overview", Published in IEEE Transactions on Vehicular Technology, vol. 60, no. 7, (2011), pp. 3386-3407.

[4] M. Cesana, F. Cuomo and E. Ekici, "Routing in Cognitive radio Network: challenges and solutions", Published in Ad Hoc Networks (Elsevier), vol. 9, no. 3, (2011), pp. 228-248.

[5] V. Kukreja, S. Gupta, B. Bhushan and C. Kumar, "Towards Performance Evaluation of Cognitive Radio Network in Realistic Environment", Published In International Journal Of Communication Networks And Information Security (IJCNIS), vol. 6, no. 1, (2014), pp. 61-77.

[6] G. Cheng, W. Liu, Y. Li and W. Cheng, "SORP: Spectrum aware on-demand routing in cognitive radio networks", Published in 2nd IEEE International Symposium on New Frontiers in Dynamic Spectrum Access Networks (DySPAN), (2007), pp. 571-574.

[7] G. Cheng, W. Liu, Y. Li and W. Cheng, "DORP: Joint on-demand routing and spectrum assignment in cognitive radio networks", Published in the International Conference on Communications (ICC), (2007), pp. 6499-6503.

[8] M. H. C.W. Pyo, "MWRP: Minimum Weight Routing based on A Common Link Control Radio for Cognitive Wireless Ad Hoc Networks", published in the International Conference on Wireless Communications and Mobile Computing (IWCMC), (2007), pp. 399-409.

[9] H. Ma, L. Zheng, X. Ma and Y. Luo, "MSCRP: Spectrum aware routing for multi-hop cognitive radio networks with a single transceiver", Published in the $3^{\text {rd }}$ International Conference on Cognitive Radio Oriented Wireless Networks and Communications (CrownCom), (2008), pp. 1-6.

[10] H. Y. Shi and Y.T, "SAMER: Spectrum Aware Mesh Routing in Cognitive Radio Networks", Published in the $3^{\text {rd }}$ IEEE Symposium on New Frontiers in Dynamic Spectrum Access Network (DySPAN), (2008), pp. 1-5.

[11] Z. Yang, G. Cheng, W. Liu, W. Yuan and W. Cheng, "Local coordination based routing and spectrum assignment in multi-hop cognitive radio networks", Published in Mobile Networks Applications (Springer), vol. 13, no. 1-2, (2008), pp. 67-81.

[12] A. Sampath, L. Yang, L. Cao, H. Zheng and B.Y. Zhao, "SPEAR: High throughput spectrum-aware routing for cognitive radio based ad-hoc networks", Published in the proceedings of 3rd International Conference on Cognitive Radio Oriented Wireless Networks and Communications (CrownCom), (2008).

[13] L. Gong, S. Deng, W. Tang and S. Li, "Anti-intermittence source routing protocol in distributed cognitive radio network", Published in the proceedings of 4th International Conference on Wireless Communications, Networking and Mobile Computing (WiCOM), (2008), pp. 1-6.

[14] G. Zhu, I.F. Akyildiz and G. Kuo, "STOD-RP: A spectrum-tree based on-demand routing protocol for multi-hop cognitive radio networks", Published in the proceedings of IEEE Global Telecommunications Conference, IEEE GLOBECOM, (2008), pp. 1-5.

[15] H. He, L. Gong, W. Tang, J. Wang and S. Li, "Spectrum-aware anti-intermittence routing in distributed cognitive radio network", Published in the proceedings of International Conference on Communications, Circuits and Systems (ICCCAS), (2009).

[16] B. Li, D. Li, Q. H. Wu and H. Li, "ASAR: ant-based spectrum aware routing for cognitive radio 
networks", Published in the proceedings of IEEE International Conference on Wireless Communications and Signal Processing (WCSP), (2009), pp. 1-5.

[17] L. Ding, T. Melodia, S. Batalama, and J. D. Matyjas, "ROSA: Distributed Joint Routing and Dynamic Spectrum Allocation in Cognitive Radio Ad Hoc Networks", Published in the proceedings of 12th ACM International conference on modelling analysis and simulation of wireless and mobile systems (MSWiM), (2009), pp. 13-20.

[18] X. Wang, T.T. Kwon and Choi, "A multipath routing and spectrum access (MRSA) framework for cognitive radio systems in multi-radio mesh networks", Published in the proceedings of ACM workshop on Cognitive radio networks (CoRoNet), (2009), pp. 55-60.

[19] R. Chowdhury and M. Di Felice, "SEARCH: A routing protocol for mobile cognitive radio ad-hoc networks", Published in the IEEE Sarnoff Symposium (SARNOFF), (2009), pp. 1-6.

[20] R. Han and X. Huang, "Reliable link routing in cognitive radio networks", Published in the proceedings of $2^{\text {nd }}$ International Asia Conference on Informatics in Control, Automation and Robotics (CAR), vol. 3, (2010), pp. 55-58.

[21] J. Chen, H. Li and J. Wu, "WHAT: a novel routing metric for multi-hop cognitive wireless networks", Published in the proceedings of $19^{\text {th }}$ Annual Wireless and Optical Communications Conference (WOCC), (2010), pp. 1-6.

[22] S. Lin and K. Chen, "SAOR: Spectrum aware opportunistic routing in cognitive radio networks", Published in Global Telecommunications Conference (IEEE), GLOBECOM, (2010), pp. 1-6.

[23] Y. Xu, M. Sheng and Y. Zhang, "TACR: Traffic-aware routing protocol for cognitive network," Published in the proceedings of IEEE $72^{\text {nd }}$ Vehicular Technology Conference (VTC), (2010), pp. 1-5.

[24] C.I. Badoi, V. Croitoru and R. Prasad, "IPSAG: An IP Spectrum Aware Geographic Routing Algorithm Proposal for Multi-hop Cognitive Radio Networks," Published in the $8^{\text {th }}$ International Conference on Communications (COMM), (2010), pp. 491-496.

[25] C.I. Badoi, V. Croitoru, N. Prasad and R. Prasad, "HC-IPSAG and GC-IPSAG Algorithm Proposals: Cluster based IPSAG Algorithm Variations for large Cognitive Radio Networks", Published in the 52 ${ }^{\text {nd }}$ International Symposium (ELMAR), (2010), pp. 239-242.

[26] M. Zeeshan, M.F. Manzoor and J. Qadir, "Backup channel and cooperative channel switching ondemand routing protocol for multi-hop cognitive radio ad hoc networks (BCCCS)", Published in the proceedings of 6th International Conference on Emerging Technologies, (ICET), (2010), pp. 394-399.

[27] Z. Zhong and T. Wei, "Cognitive routing metric with improving capacity (CRM-IC) for heterogeneous ad hoc network" , Published in the proceedings of the International Conference on Information Networking and Automation (ICINA), vol. 1, (2010), pp. 271-274.

[28] S. Ding and L. Liu, "A Node-disjoint Multipath Routing Protocol Based on AODV", Published in International Symposium on Distributed Computing and Applications to Business, Engineering and Science, (2010), pp. 312-316.

[29] A. Abbagnale and F. Cuomo, "Gymkhana: A Connectivity-based Routing Scheme for Cognitive Radio Ad Hoc Networks", Published in the proceeding of IEEE conference on Computer Communication Workshops (INFOCOM), (2010), pp. 1-5.

[30] I. Beltagy, M. Youssef and M. El-Derini, "A new routing metric and protocol for multipath routing in cognitive networks", Published in the proceeding of IEEE Wireless Communications and Networking Conference (WCNC), (2011), pp. 974-979.

[31] S. M. Kamruzzaman, E. Kim and D. G. Jeong, "Spectrum and energy aware routing protocol for cognitive radio ad hoc networks", Published in the proceeding of IEEE International Conference on Communications (ICC), (2011), pp. 1-5.

[32] S.M. Kamruzzaman, E. Kim and D.G. Jeong, "EQR: An energy efficient QoS routing protocol for cognitive radio and ad hoc networks", Published in 13th International Conference on Advance Communication Technology (ICACT), (2011), pp. 344-349.

[33] A. C. Talay and D. T. Altilar, "UNITED nodes: cluster-based routing protocol for mobile cognitive radio networks", Published in the IET Communications (IET), vol. 5, no. 15, (2011), pp. 2097-2105.

[34] K. Zheng, H. Li, R. C. Qiu and S. Gong, "MORL: Multi-objective reinforcement learning based routing in cognitive radio networks: walking in a random maze", Published in the proceeding of IEEE International Conference on Computing, Networking and Communications (ICNC), (2012), pp. 359363.

[35] M.A. Hoque and X. Hong, "BioStaR: a bio- inspired stable routing for cognitive radio networks", Published in the Proceedings of IEEE International Conference on Computing, Networking and Communications (ICNC), (2012), pp. 402-406.

[36] A.S. Cacciapuoti, M. Caleffi and L Paura, "CAODV: Reactive routing for mobile cognitive radio ad hoc networks", Published in Journal of Ad Hoc Networks (Elsevier), vol. 10, no. 5, (2012), pp. 803-815.

[37] M.A. Rahman, M. Caleffi and L. Paura, "D2CARP: Joint path and spectrum diversity in cognitive radio ad-hoc network", Published in EURASIP Journal on Wireless Communications and Networking, (2012).

[38] F. Tang, L. Barolli and J. Li, "MP-JCRCA: A Joint Design for Distributed Stable Routing and Channel Assignment Over Multi-Hop and Multi-Flow Mobile Ad Hoc Cognitive Networks", IEEE Transactions Industrial Informatics, vol. 10, no. 2, (2012), pp. 1606-1615.

[39] A. P. Namanya and J. Pagna-Disso, "PRP-HOL AND PRP-EOL: Performance Modelling and Analysis 
of the Delay Aware Routing Metric in Cognitive Radio Ad Hoc Networks", Published in the proceedings of $6^{\text {th }}$ joint IFIP Wireless and Mobile Networking Conference (WMNC), (2013), pp. 1-8.

[40] K. Habak, M. Abdelatif, H. Hagrass, K. Rizc and M. Youssef, "LAUNCH: A Location-Aided Routing Protocol for Cognitive Radio Networks", Published in the proceedings of International Conference on Computing, Networking and Communications (ICNC), (2013), pp. 729-733.

[41] E. Masri, "A fuzzy-based routing strategy for multihop cognitive radio networks", Published in International Journal of Communication Networks and Information Security (IJCNIS), vol. 3, no. 1, (2011), pp. 74-82.

[42] J. Deng, Y.S. Han, P.N. Chen and P.K. Varshney, "Optimal Transmission Range for Wireless Ad Hoc Networks Based on Energy Efficiency", Published in IEEE Transactions on Communications, vol. 55, no. 9 , (2007), pp. 1772-1782.

[43] V. Rodoplu and T.H. Meng, "Minimum Energy Mobile Wireless Networks", IEEE J. Selected Areas in Comm, vol. 17, no. 8, (1999), pp. 1333-1344.

[44] C.K. Nagpal, M. Kaur, S. Gupta and B. Bhushan, "Impact of Variable Transmission Range on Manet Performance", Published in International Journal of Ad hoc, Sensor and Ubiquitous Computing (IJASUC), vol. 2, no. 4, (2011).

[45] K. Garg, Pratibha and S. Gupta, "A Novel Routing Strategy for Cognitive Radio Ad Hoc Network", Accepted for publication in the proceedings of International Conference on Computing for sustainable global development, INDIAcom, (2015).

[46] S. Gupta, B. Bhushan and V. Kukreja, "A Fuzzy based routing Protocol for Cognitive Radio Networks", Published in International Journal of Fuzzy Computation and Modelling (Inderscience), (2014).

[47] P. Mittal, M. Jain, C.K. Nagpal and S. Gupta, "A Throughput and Spectrum Aware Fuzzy Logic Based Routing Protocol for CRN", Published in International Journal of Computer Network and Information Security (IJCNIS), vol. 8, no. 3, (2016), pp. 58-64.

[48] C. K. Nagpal Poonam, and S. Gupta, "A Delay and Spectrum Aware Fuzzy Logic Based Routing Protocol for CRN", Published in International Journal of Computer Networks and Applications (IJCNA), vol. 3, no. 1, (2016), pp. 16-24. 